\title{
ESTATUTO DA FAMÍLIA: ANÁLISE DO DISCURSO DE PARLAMENTARES
}

\author{
ESTATUTO DE LA FAMILIA: \\ ANÁLISIS DEL DISCURSO DE PARLAMENTARIOS \\ FAMILY STATUTE: \\ DISCOURSE ANALYSIS OF PARLIAMENTARIANS
}

Jerbbson Dias dos Santos ${ }^{1}$ e Thelma Maria Grisi Velôso' ${ }^{1}$

${ }^{1}$ Universidade Estadual da Paraíba, Campina Grande/PB, Brasil

RESUMO: Neste artigo, analisa-se o discurso de deputados de uma comissão especial, numa reunião destinada a proferir parecer para o Projeto de Lei $n^{\circ}$ 6583/2013, que dispõe sobre o Estatuto da Família. O projeto defende uma definição de entidade familiar que exclui diversos arranjos familiares menos tradicionais. Identificaram-se os argumentos com conteúdo religioso que são favoráveis ou contrários ao Estatuto e se analisou como os parlamentares constroem a factualidade dos seus discursos, ou seja, sua credibilidade argumentativa. A perspectiva teórico-metodológica escolhida foi a Psicologia Social Discursiva. Observou-se que a construção da factualidade discursiva ampara-se no conteúdo religioso dos argumentos e que os argumentos religiosos ganham fidedignidade através das estratégias retóricas de factualidade. É possível distinguir os argumentos dos deputados favoráveis, e dos contrários, apenas em termos de conteúdo, pois, em termos de emprego de dispositivos argumentativos, ambos são equivalentes, já que utilizam estratégias discursivas similares e recorrem ao discurso religioso.

PALAVRAS-CHAVE: Estatuto da Família; Discurso religioso; Análise do discurso; Psicologia Social Discursiva.

RESUMEN: En este artículo se analiza el discurso de los diputados de una comisión especial en una reunión destinada a opinar sobre el Proyecto de Ley n ${ }^{\circ}$ 6583/2013, que trata del Estatuto de la Familia. El proyecto de ley aboga por una definición de entidad familiar que excluya varios arreglos familiares menos tradicionales. Se identificaron argumentos con contenido religioso que son favorables o contrarios al Estatuto y se analizó como los parlamentarios construyen la facticidad de sus discursos, es decir, su credibilidad argumentativa. La perspectiva teórico-metodológica elegida fue la Psicología Social Discursiva. Se observó que la construcción de la facticidad discursiva se sustenta en el contenido religioso de los argumentos y que los argumentos religiosos ganan confiabilidad a través de estrategias de facticidad retórica. Es posible distinguir los argumentos de los diputados a favor y los en contra solo en términos de contenido, porque, en términos del uso de dispositivos argumentativos, ambos son equivalentes, ya que utilizan estrategias discursivas similares y recurren al discurso religioso.

PALABRAS CLAVES: Estatuto de la Familia; Discurso religioso; Análisis del discurso; Psicología Social Discursiva.

ABSTRACT: In this article we analyze the speech of representatives of a special commission in a meeting destined to give an opinion for the Bill (PL) $n^{\circ} 6583 / 2013$, which deals with the Statute of the Family. The bill advocates a definition of a family entity that excludes less traditional family arrangements. Arguments with religious content that are favorable or contrary to the Statute were identified and the way parliamentarians build the factuality of their speeches, that is, their argumentative credibility, was analyzed. The theoretical-methodological perspective chosen was Discursive Social Psychology. It was observed that the construction of discourse factuality is supported by the religious content of the arguments and that the religious arguments gain reliability through rhetorical factuality strategies. It is possible to distinguish the arguments of representatives in favor, and those against, only in terms of content, because, in terms of the use of argumentative devices, both are equivalent, as they use similar discursive strategies and resort to religious discourse.

KEYWORDS: Family Statute; Religious discourse; Discourse Analysis; Social Discursive Psychology. 


\section{Introdução}

A Constituição Federal de 1988 reverteu prejuízos causados à cidadania do povo brasileiro duramente dilapidada durante a Ditadura Militar (1964-1985). A Constituição reflete as contradições entre a vontade política, as limitações institucionais e as necessidades sociais e garante conceitos democráticos fundamentais, como o princípio da igualdade entre homens e mulheres, o respeito às diferenças de credo e de cor e os direitos universais à saúde e à educação (Montambeault, 2018; Rocha, 2008). Entretanto, interesses que ameaçam esses direitos estão sempre à espreita e, ocasionalmente, recrudescem no cenário político, plasmados na natureza argumentativa e retórica do discurso (Billig, 2008).

Um dos projetos de lei recentes mais representativos desse embate argumentativo é o denominado PL no 6583/2013 - 'Estatuto da Família'. Uma comissão especial de deputados foi criada para tratar especificamente desse projeto. Esse tipo de comissão é criada para examinar e dar parecer sobre alguns tipos de proposições, como Propostas de Emendas à Constituição - PEC, projetos que envolvam matéria de competência de mais de três comissões de mérito ou projeto de alteração do Regimento Interno (Câmara dos Deputados, 2020a).

De autoria do deputado Anderson Ferreira (PR-PE), esse projeto é apresentado como uma tentativa de regulamentar a atenção à família nas políticas públicas do país, e oferece uma definição operacional de entidade familiar que delimita os arranjos familiares que devem ser considerados prioritários nessas políticas. Segundo alguns deputados da comissão, favoráveis ao projeto, a delimitação proposta direcionará eficazmente os programas e os recursos públicos, otimizando a assistência aos arranjos familiares mais tradicionais, além de ser uma definição que está presente na Constituição Federal. Entretanto, para os deputados contrários, essa definição deixa de contemplar os demais arranjos, também representativos e menos tradicionais, e afeta diretamente o reconhecimento da união de pessoas do mesmo sexo como família, o que vai de encontro a um dos objetivos fundamentais da República Federativa do Brasil, que é o de "promover o bem de todos, sem preconceitos de origem, raça, sexo, cor, idade e quaisquer outras formas de discriminação" (Constituição Federal, 1988).

Dos 26 deputados que se expressaram como favoráveis ao projeto, na derradeira sessão da comissão especial, 15 são signatários da Frente Parlamentar Evangélica do Congresso Nacional (FPE), incluindo o presidente da comissão e o autor do projeto. Os demais são signatários da Frente Católica ou das duas Frentes, como o relator do projeto. Já dos deputados contrários ao projeto - quatro - nenhum é signatário de quaisquer frentes.

Diversos autores reconhecem que as atividades legislativas recebem uma influência religiosa (Antunes, 2016; Aquino, 2015; Camurça, 2019; Mountian, 2016; Paiva, 2016; Silva, 2017; Trevisan, 2013). Existem práticas que indicam que há uma ocorrência de atividades devocionais na Câmara, como cerimônias religiosas. Apesar das melhorias, em termos de direitos civis, há "o retorno de um forte discurso religioso e moralizante na política” (Mountian, 2016, p. 42).

Na história do Brasil, a influência da religião na política não é recente, já que a Igreja Católica esteve presente na elaboração da Constituição de 1934; no apoio dado ao Golpe Militar de 1964 e na instauração do Regime Militar; no papel político desempenhado pela Teologia da Libertação (TL) e pelas Comunidades Eclesiais de Base (CEBs). 
A ascensão dos pentecostais e neopentecostais a partir dos anos 1980, atores sociais importantes na elaboração da Constituição de 1988, resultou, na atualidade, numa das principais bancadas do Congresso Brasileiro. A ideia de conservar a família tradicional nuclear cristã passou a ser uma das grandes metas desses parlamentares (Silva, 2017).

O fim do Século XX e o início do XXI testemunharam o surgimento de várias mudanças sociais que atingiram, inclusive, espaços tradicionais, como a família e a religião. Entretanto, essas mudanças não implicaram uma destruição total de práticas e valores e fizeram “coexistir o 'novo' e o 'tradicional' numa mesma sociedade” (Ribas, 2008, p. 254, grifos da autora).

Considerando a forte influência de frentes parlamentares religiosas e que a proposta de Estatuto visa transformar radicalmente a atenção à família no país, interessou-nos analisar o discurso religioso dos deputados na sessão de conclusão dos trabalhos da comissão especial destinada a proferir parecer para o projeto, verificar como procedem para que suas descrições pareçam fiéis à realidade, e identificar os principais argumentos contrários e/ou favoráveis fundamentados no discurso religioso empregados para criticar ou defender esse projeto de lei.

Essa análise se fundamenta na perspectiva teórico-metodológica da Psicologia Social Discursiva (Billig, 2008; Edwards, 1997; Edwards \& Potter, 1992; Potter, 1998; Potter \& Wetherell, 1987). Essa perspectiva e sua respectiva análise de discurso surgiram baseadas na Semiótica, na Filosofia da Linguagem, na Sociologia do conhecimento científico e nos primeiros desenvolvimentos teóricos pós-estruturalistas com ênfase na linguagem, como a Análise Conversacional e a Etnometodologia. A partir de conceitos como ação, variabilidade, retórica e construção, procura identificar como as expressões orais ou escritas são construídas para realizar ações discursivas que variam de acordo com os argumentos utilizados. As descrições realizam ações e constroem fatos.

Essa abordagem é diferente de outras, como a cognição social, porque, em vez de partir de processos cognitivos internos, de comportamentos regulares ou de eventos de ordem neurológica, volta-se para a interação discursiva, para as construções empregadas pelos participantes e a orientação que eles adotam em suas interlocuções em situações cotidianas ou em contextos institucionais (Potter, 2012).

\section{Método}

Nesta pesquisa, adotou-se uma abordagem qualitativa fundamentada no arcabouço teórico-metodológico da Psicologia Social Discursiva. O corpus de análise foi o áudio transcrito da reunião do dia 8 de outubro de 2015 , da comissão especial da Câmara de Deputados destinada a proferir parecer para o projeto de lei $\mathrm{n}^{\circ} 6583$, que dispõe sobre o Estatuto da Família. Como se trata de uma pesquisa documental com arquivos de domínio público, não foi necessário submeter o projeto ao Comitê de Ética em Pesquisa.

Os critérios utilizados para a escolha desta sessão foram a participação dos deputados e o estágio de desenvolvimento dos debates. Optou-se por uma sessão com número significativo de parlamentares e, a mais recente, com o estágio de discussão mais atualizado. Essa sessão é a de conclusão dos trabalhos da comissão, que só serão retomados depois da deliberação do projeto pela Mesa Diretora da Câmara dos Deputados. 
Os participantes da pesquisa são deputados federais da $55^{\mathrm{a}}$ Legislatura da Câmara dos Deputados, de quinze partidos diferentes, cujas identidades foram veladas com o uso de pseudônimos, pois, apesar de serem falas disponíveis ao público, sua interpretação é particular e pode não representar o que o (a) deputado (a) em questão tentou expressar. O número de deputados que falaram foi de $30-26$ homens e quatro mulheres - embora em ata esteja registrada a presença de 58 deputados, entre membros e não membros da comissão (Câmara dos Deputados, 2020b). A reunião durou aproximadamente 308 minutos.

Foram registradas 165 falas nesta sessão, excluídas as intervenções dos deputados quando exercem a função de presidente da comissão, já que suas pontuações têm o objetivo de organizar os trabalhos. A fala à qual os deputados têm direito varia de 3 a 10 minutos, a depender da atividade realizada na sessão. Na maior parte do tempo, porém, a fala dura cinco minutos. Com denotação religiosa, foram identificadas 29 falas.

$\mathrm{Na} 55^{\mathrm{a}}$ legislatura (2015-2019), foram registradas 345 frentes parlamentares. Cada deputado pode fazer parte de quantas frentes quiser (Câmara dos Deputados, 2020c). Neste trabalho, foram consideradas as frentes que têm relação com seu escopo: Frente Parlamentar Mista Católica Apostólica Romana e Frente Parlamentar Evangélica do Congresso Nacional (FPE). Eram signatários das duas frentes seis deputados das legendas: PHS/PR, PSB/MS, PSC/SP, SD/RJ, PSB/SP e PROS/MG; dois, só da Frente Parlamentar Mista Católica: PSOL-RJ e PHS-AL; e quinze apenas da FPE das legendas: DEM/AC, PR/PE, SD/RJ, PR/CE, PHS/RR, PV/SP, PSD/PR, PSDB/SC, $\mathrm{PSD} / \mathrm{SP}, \mathrm{PRB} / \mathrm{GO}, \mathrm{DEM} / \mathrm{RO}, \mathrm{PHS} / \mathrm{PE}, \mathrm{PSC} / \mathrm{MT}, \mathrm{PRB} / \mathrm{AM}$ e DEM/RJ. Não eram signatários de nenhuma dessas duas frentes sete deputados das siglas PTN-BA, PSDB-AM, PT-DF, PSOL-RJ, DEM-SP, PT-RS e PSDB-RN. Algumas dessas legendas não existem mais. Umas foram incorporadas a outros partidos, e outras mudaram de nome.

O método utilizado para analisar o discurso tem diferentes estágios, que não são sequenciais, mas lugares por onde o pesquisador avança e aos quais retorna durante todo o processo de análise. Nesta pesquisa, depois de transcrever o áudio da gravação completa da reunião, passamos para a etapa da codificação, em que as categorias são as mais inclusivas possíveis. Na etapa seguinte, a da análise propriamente dita, atentamos para os recursos empregados pelos narradores, como a variação, o detalhe, a retórica, a responsabilidade, o interesse e a conveniência (Potter, 2004, 2012).

Consideramos discurso religioso toda e qualquer referência, na fala dos deputados, a entidades metafísicas (Deus, anjo etc.), documentos religiosos históricos (a Bíblia), personalidades ligadas à religiosidade (Jesus, Paulo de Tarso, Papa Francisco etc.), termos e conceitos ligados a alguma religião (dogma, fé, criacionismo etc.) e menções diretas à palavra 'religião' e derivadas (religioso, religiosidade, religionário, religiosamente etc.).

\section{Relatos dos parlamentares: análise e discussão}

Identificaremos, a seguir, em trechos das falas dos parlamentares, o discurso religioso utilizado por eles para conferir fidedignidade aos seus discursos, e apontaremos os principais argumentos favoráveis ou contrários ao projeto do Estatuto da Família. É necessário apresentar uma descrição do início da reunião para que a primeira fala, que traz um argumento referente à religião, torne-se inteligível. Depois de aberta a reunião, a décima quarta da comissão, o presidente informou aos presentes que havia 
um requerimento de inversão de pauta de autoria do relator do projeto, o deputado Vítor Cunha (PHS/PR), com o objetivo de priorizar a votação das alterações propostas ao projeto e só votar a ata da reunião anterior no final dos trabalhos. A fala seguinte é da deputada Leila Ribeiro (PT/DF), contrária ao projeto, que se dispôs a contraditar o requerimento:

Eu me pergunto que celeridade é essa que se quer. Que celeridade que se quer na exclusão dos arranjos familiares? Que celeridade que se quer prá institucionalizar uma lógica homofóbica e excludente? Que celeridade que se quer para esterilizar as, das famílias o afeto, que é tão fundamental para a construção de todos os seres humanos? Que celeridade que se quer para estar se rompendo a laicidade do Estado?

Alguns turnos de fala depois, o deputado Roni Evandro (PROS-MG), favorável ao projeto, respondeu às questões da deputada:

Nós que lemos e relemos o Estatuto, o relatório do nosso nobre colega deputado Vítor Cunha, sabemos e está claro, e hoje os próprios meios de comunicação estão refletindo isso, nós não estamos, é..., tirando direito de ninguém, nós não estamos desmerecendo ou diminuindo qualquer tipo de relação ou de relacionamento, pelo contrário, assim como temos, por exemplo, o exemplo do Papa Francisco, que, mesmo contundente, é..., dizendo a favor da família, fez questão de visitar os Estados Unidos, visitar, é..., amigos que são homoafetivos e que vivem juntos e o receberam com todo o respeito assim como foram tratados.

A deputada Leila Ribeiro (PT/DF) afirma que a inversão de pauta está ligada ao fato de os deputados favoráveis ao projeto pretenderem 'institucionalizar' a homofobia, 'esterilizar o afeto' das famílias e 'romper' a laicidade do Estado. Acusa os defensores do projeto de seguirem um preceito religioso ao firmar a definição de família como a união de um homem e de uma mulher, o que impede que os casais do mesmo sexo sejam reconhecidos como família, e de legislarem com base na religião.

Utilizar-se desse preceito religioso para fundamentar uma lei é, de acordo com os deputados contrários ao projeto, sobrepor os interesses religiosos aos interesses de todos os cidadãos brasileiros. Tal formulação do caso é uma acusação de descumprimento da laicidade do Estado. Por estar prevista na Constituição Federal, qualquer violação a esse caráter laico é inconstitucional.

Apesar de a Constituição Federal não apresentar patentemente a laicidade como um de seus princípios fundamentais, estabelece todos os pressupostos que fundamentam um Estado laico, como a garantia da liberdade e da igualdade dos seus cidadãos e a separação entre Estado e religião (Zylberstayn, 2012, citado por Paiva, 2016). Em seu Artigo 19, inciso I, a Constituição veda a todos os entes federativos o estabelecimento de cultos religiosos ou igrejas (Constituição Federal, 1988).

Ao dizer que o Papa, a maior autoridade da Igreja Católica, foi quem teve tal atitude de respeito, o deputado Roni Evandro sugere uma generalização dessa postura para todos os membros dessa religião, invalida a tese dos deputados contrários ao projeto de que há uma relação entre homofobia e religião, sem se reportar à quebra da laicidade, e constrói a ideia de que o pontífice está entre os que estão a favor de sua própria definição 
de família, como a união entre homem, mulher e filhos. O Papa, "dizendo a favor da família, fez questão de ... visitar, é..., amigos que são homoafetivos”. Já que não há espaço para casais do mesmo sexo na definição de família que defende, ele afirma, vagamente e com certa hesitação, que essas pessoas são 'dois amigos que vivem juntos'. Esse uso diverso de termos para descrever esse fato é um exemplo de seleção de categorias. Para a Psicologia Social Discursiva, a categorização é um processo discursivo, e não mental, e exerce um papel fundamental na construção de identidades e de grupos e na descrição da realidade. O sentido de algo se constitui por meio da categorização, e uma categoria pode ser construída de maneiras diferentes (Potter, 1998).

A seguir, a mesma deputada enfatiza o desrespeito ao Estado laico e aponta, mais explicitamente, como essa questão se materializa na fala dos congressistas:

Leila Ribeiro: A Lei Maria da Penha também assegura que as mulheres vítimas de violência não podem ficar na condição indissolúvel da família, que é uma concepção religiosa, as concepções religiosas que são legítimas e devem ser preservadas, mas elas não podem invadir o âmbito do Estado, porque senão se rompe a laicidade.

Nessa fala da deputada, podemos observar o uso de um recurso argumentativo que Semin e Manstead (1983 citado por Potter \& Wetherell, 1987) chamam de disclaimer ou atenuador, utilizado quando se quer evitar que uma fala desagradável atinja a imagem daquele que a profere. Faz-se uma 'concessão aparente' antes da fala problemática. No trecho destacado, a deputada protege-se de possíveis acusações de ateísmo ou hostilidade à religião, afirmando que as "concepções religiosas ... são legítimas e devem ser preservadas”. Em seguida, porém, vem a opinião que desagrada aos seus opositores de que "[ tais concepções] não podem invadir o âmbito do Estado, porque senão se rompe a laicidade."

Prosseguindo com a mesma linha de argumentação, a deputada chama atenção para uma 'função' característica de alguns deputados favoráveis que não deveria ser exercida naquele momento:

Leila Ribeiro: Eu entendo que haja uma concepção religiosa, uma concepção religiosa que foi expressa e é expressa várias vezes do lugar de quem está exercendo esta função religiosa, mas não no lugar de quem está aqui para defender direitos, prá defender legislação e defender a laicidade do Estado e defender a dignidade humana.

Expressar e defender uma ideia religiosa é compatível com a "função religiosa", mas é incompatível com a função de "defender legislação". Está implícito o uso de duas posições identitárias que não recebem nomes, mas a deputada se reporta às funções de 'pastor' e de 'deputado'. Essas profissões têm o "lugar" onde devem ser exercidas, mas "aqui" no Congresso Nacional - é o lugar de "defender a laicidade do Estado", portanto, não cabe praticar a "função religiosa". Em sua fala, a deputada adota uma estratégia discursiva chamada de 'formulação de roteiro'. Como diz Potter (1998, p. 253, tradução nossa), "as ações que se produzem em uma relação de casal ou em um debate político podem apresentar-se como algo normal e corriqueiro ou podem ser minadas apresentando-se como algo estranho ou anormal”. No caso que analisamos, a congressista formula o que se espera da conduta 
normal ou rotineira de um deputado da Casa, e acusa seus opositores de fugirem dessa formulação. Nesse caso, os deputados favoráveis ao projeto deixam de 'defender a legislação', que é a conduta esperada, para exercer a 'função religiosa' - a conduta estranha.

Antunes (2016), em um estudo com relatos de parlamentares, identifica os congressistas através de duas categorias: 'deputado' e 'deputado pastor', e afirma que são os próprios parlamentares religiosos que incluem em seus nomes oficiais a designação 'pastor'. $\mathrm{O}$ autor questiona essa denominação, considerando que o Congresso deve ser um lugar pautado pela ética e pelo respeito à laicidade.

Dos deputados que estiveram presentes na sessão objeto de nossa análise, havia, pelo menos, cinco que são pastores evangélicos, mas apenas dois se denominam 'deputados pastores', todos os cinco são favoráveis ao projeto. Os outros três, apesar de não optarem oficialmente pelo título de 'pastor', são referidos ocasionalmente nas falas da sessão como se pastores fossem. Há também um 'deputado missionário' e um 'deputado irmão' na mesma comissão. O argumento da deputada Leila Ribeiro (PT/DF) de que há uma "função religiosa" sendo exercida por alguns parlamentares encontra respaldo na utilização desses títulos.

Reportando-se à fala da deputada Leila, o deputado Mateus Barbosa (PV-SP), favorável ao projeto, apresenta, em seguida, um argumento que aproxima a 'função religiosa' da defesa da dignidade e diz que foram as religiões cristãs que historicamente lutaram pela dignidade humana, exatamente o que a deputada afirmou que não tem sido defendido. Coloca-se como defensor da dignidade dos homossexuais, apesar de hesitar - "qualquer pessoa homossexual terá, sim, guardiões, guardiões da sua digne... da sua dignidade”. Assim, afasta-se da acusação de homofobia.

A té esse momento da sessão, há uma proibição implícita de justificar uma posição com base em preceitos religiosos. Se fosse empregado pelos deputados contrários, dissolver-seia o contraste entre a 'função religiosa' e a função legislativa, pois os próprios acusadores seriam os acusados. Se empregado pelos deputados favoráveis ao projeto, assumir-se-iam a 'função religiosa' e o consequente desrespeito ao Estado laico, além das acusações de homofobia, impossibilitando a continuidade da tramitação do projeto. Porém, um deputado que não fazia parte da comissão lançou mão de uma possibilidade regimental e pediu tempo de liderança para expor sua opinião. Líder de um partido contrário à aprovação do projeto, Nicolas Barros (PSOL/RJ) reportou-se, como veremos abaixo, à fala do deputado Rodrigo Castro (PRB/GO). Apesar de ser do PRB, o deputado Rodrigo Castro ocupa uma vaga reservada ao PSDB na comissão e, lamentando a 'divisão' entre contrários e favoráveis à família, disse: "O PSDB é pela família, o PSDB se coloca numa posição contrária àqueles que estão aqui e se posicionam contra a família, nós somos a favor da família ... o PSDB é pró-família”.

Nicolas Barros: Eu que tenho uma história de vida vinculada ao mundo religioso, graças a Deus, me permito dizer isso num ambiente laico e plural, fico muito espantado quando a gente traz prá vida civil o dogma, quando meu amigo, deputado Rodrigo [Castro] diz que aqui há uma divisão entre os que são a favor da família e os que são contra, ele traz de maneira nada social democrata a estátua pétrea do dogma, porque ao longo da história humana, a comunidade amorosa, afetiva, entre pessoas mudou muito. 
O deputado inicia a fala dizendo que sua vida está historicamente ligada ao "mundo religioso" e assume uma posição até então proibida pelas circunstâncias argumentativas. Fala "graças a Deus", uma expressão religiosa que reforça a posição assumida. Também diz que o ambiente em que se encontra é "laico e plural", uma imagem exatamente contrária à que os deputados opositores, seus aliados, desejavam construir. Reporta-se à fala do deputado Rodrigo Castro e, em seguida, posiciona-se contra o dogma na vida civil. Em vez de criticar a influência da religião como um todo, o deputado especifica um aspecto da religião que não pode estar presente na vida não religiosa do Congresso. Essa postura gera uma ambiguidade que, mais à frente, trará consequências para o conteúdo dos argumentos dos deputados, o qual se tornará abertamente religioso, o que não vinha sendo até então.

O deputado Nicolas continuou, em outros trechos de sua fala, empregando termos e frases religiosas, inclusive, referindo-se à Bíblia, para sustentar seus argumentos e persuadir seus opositores a concordarem com ele. Depois de mais uma fala da deputada Leila Ribeiro (PT/DF), em que apoia suas colocações, o deputado Pastor Paulo (PHS/PE) critica o pedido de tolerância do deputado Nicolas e afirma:

Interessante é que nós temos que assistir coisas aqui que não dá prá entender, alguém que vem aqui, aparece aqui de supetão e depois desaparece [o deputado Nicolas já havia saído], e vem falar sobre lições de amor bíblico, eu gostaria de poder passar umas duas, três, quatro, cinco horas conversando com essa pessoa, já que citou Bíblia, prá gente conversar dentro da Bíblia, aí é outro departamento, até porque, em nenhum momento do relatório apresentado aqui, o relator apresentou nada de cunho religioso e estão tentando levar para o lado da religiosidade o relatório apresentado aqui, que não tem nada a ver.

Ao se referir ao fato de o deputado Nicolas ter citado a Bíblia, o Pastor Paulo afirma que "aí é outro departamento", lembrando que o relator do projeto não fez nenhuma menção religiosa em seu relatório, reconhecendo, ao mesmo tempo, que os deputados contrários têm a intenção de caracterizar o relatório como religioso. Ele mostra que entende da Bíblia, mas evita trazer argumentos religiosos como os do deputado Nicolas, para não confirmar a versão dos deputados contrários de que há concepções religiosas vinculadas ao projeto do Estatuto. Apesar de ser um 'deputado pastor', ele desfaz a expectativa do que se espera de sua posição identitária e mantém a acusação de desrespeito à laicidade longe de lhe ser atribuível.

Sua fala foi apoiada, em seguida, pelo deputado Rafael Sales (PSB/SP), que reforçou que os debates da comissão não eram religiosos, disse que não estava "levantando bandeiras", ao contrário de outros deputados que levantam bandeiras "ideológicas, marxistas e feministas", e que estava tratando da "família de fato", que precisa ser "defendida, preservada, valorizada e protegida", sugerindo que existe uma forma completamente desinteressada de defini-la. Assim, afirmou-se neutro e apontou interesses na fala do adversário, o que é um exemplo claro de 'gestão de interesses'. 'Vacinou-se' contra a acusação de conveniência e acusou o opositor de ter suas afirmações movidas por interesses das mais diversas ordens. A 'vacinação' contra a conveniência favoreceu a credibilidade e a factualidade da descrição e eliminou a atribuição de conveniência (ver Potter, 1998). 
A fala do deputado Nicolas Barros (PSOL/RJ) abriu um precedente discursivo inusitado. Posicionando-se contra o interesse religioso em matérias civis, ele citou o livro sagrado dos católicos e dos evangélicos. Isso motivou os deputados favoráveis à aprovação do Estatuto, que, até aquele momento, contiveram a expressão de sua religiosidade para evitar acusações de interesse religioso sobre o interesse civil, a se mostrarem abertamente como religiosos, direta ou indiretamente, uma vez que o 'outro lado' abriu mão dessa restrição.

O deputado Breno Silva (PHS/AL), favorável ao projeto, é um exemplo desse momento de abertura, uma vez que assumiu sem escrúpulos sua posição: "eu tenho oito mandatos e em uma linha defendo a família neste modelo tradicional.” Afirma também que foi ao Congresso não para representar o povo, mas uma "fatia" dos brasileiros, dando a entender que, ao defender essa parcela, pode deixar o todo em segundo plano, o que dá margem à compreensão de que ele está sujeito a defender os direitos de uns em detrimento dos de outros: "é um equívoco dizer que o deputado representa o povo brasileiro. Não, eu represento uma fatia do povo brasileiro, porque aqui é proporcional...” Adiante, o deputado continua a fazer declarações que afirmam o seu posicionamento como religioso interessado em aprovar o projeto:

Porquanto, reafirmo, estou aqui em nome desta causa, prá mim, tem uma lei de Deus, e a Bíblia Sagrada e a lei dos homens, que é aquilo que nós tamo fazendo, nós num pudemos rasgar a lei de Deus, Deus fez o homem para a mulher, fez Adão e Eva e, não, Adão e Ivo, muito obrigado, senhor presidente.

As acusações dos deputados contrários, rebatidas desde o início da sessão, são praticamente confirmadas nessa fala do deputado. Ele afirma que defende uma "causa", evidentemente religiosa, que não pode "rasgar a lei de Deus", sobrepondo, assim, o interesse religioso ao interesse do Estado, e finaliza com um comentário homofóbico: 'Deus fez Adão e Eva, e não, Adão e Ivo'. Os dois contrastes, 'religiosos versus Estado' e 'religiosos versus homossexuais', são exemplificados nessa fala. Não faria sentido o deputado usar esses argumentos se não tivessem eficiência retórica entre seus pares, pois nenhum dos deputados favoráveis discordou do argumento ou o criticou. O silêncio dos favoráveis, ou seja, o que não é dito por eles, é tão significativo quanto o que é dito. Nesse momento da sessão, apresentar-se como cristão é uma condição necessária para ser respeitado e sua fala ser levada em consideração.

Nos turnos seguintes, os deputados já não mais se defendem da acusação de exercer uma função religiosa, mas se concentram em defender a definição de família pelos meios 'legais' e contestar o significado de laicidade. Em seu Artigo 2oㅡ o Projeto de Lei em questão define a entidade familiar como "o núcleo social formado a partir da união entre um homem e uma mulher, por meio de casamento ou união estável, ou ainda por comunidade formada por qualquer dos pais e seus descendentes" (Câmara dos Deputados, 2015). Os deputados defendem que não é possível modificar essa definição porque isso contraria a Constituição Federal, em cujo Artigo 226, parágrafo 3ํㅡㄹ consta que, "para efeito da proteção do Estado, é reconhecida a união estável entre o homem e a mulher como entidade familiar, devendo a lei facilitar sua conversão em casamento." Reformulou-se a acusação de descumprimento à laicidade em termos de manutenção da legalidade. Ao mesmo tempo em que se defendem da denúncia de desrespeito à Constituição pelo princípio da laicidade, posicionam-se como defensores da mesma Constituição ao empregar os termos de um dos seus artigos. 
O deputado Mateus Barbosa (PV-SP), também favorável ao projeto, vai além e propõe outro termo:

O laicismo é diferente de laicidade, por quê? Porque o laicismo clássico, já que muitas vezes externado, ele, sobre a pretensão de gerar uma neutralidade no Estado, ele quer gerar na verdade uma neutralização, não é neutralidade, é neutralização, neutralidade é não discutirmos quais são nossas orientações religiosas, mas não há dúvida que há, que uma determinada orientação religiosa pode influenciar na vida da pessoa.

Embora a defesa da laicidade seja a expressão mais clara do contraste 'religiosos versus Estado', ela é reivindicada por ambos os lados - os favoráveis ao projeto e os que são contrários a ele. Sua definição, porém, torna-se objeto de contenda, com o conceito de 'laicismo' sendo oferecido como alternativa. Segundo Vital e Lopes (2013, p. 4), para atores religiosos, laicidade significa "a separação ou a independência do Estado em relação à religião”, e laicismo é “a negação (e não, a separação) do religioso” da esfera estatal. Defende-se, assim, a "igualdade" no tratamento do Estado para as diferentes religiões e a religião como mais um grupo de "pressão político-social”, com o mesmo direito de utilizar o espaço social como outros grupos e movimentos.

O deputado Pastor Paulo (PHS/PE), em outro turno, faz distinções entre as opções religiosas dos presentes e procura relacioná-las à defesa da família:

... se criou esse estigma que os evangélico tão querendo acabar com a família no Brasil, se tem alguém que defende os evangélico no Brasil, ou, ou, as família no Brasil são os evangélicos e os católicos sérios neste Brasil, eu acho que a vergonha para os verdadeiros católicos neste Brasil é ouvir pessoas se dizerem católicos aqui e vir defender essas barbáries que vão de encontro à família, atitudes que destroem a família tradicional, eu acho que nós estamos tendo oportunidade de dar uma resposta à própria sociedade de uma maneira muito especial.

Para ser bem sucedido em sua argumentação, o deputado dividiu os católicos em sérios e não sérios. Assim, criou uma nova categorização (Billig, 2008), que serviu para sua ação discursiva, incluindo na categoria "sérios" os colegas favoráveis ao projeto e excluindo os contrários. Com esse manejo de categorias, o deputado pastor teve o apoio dos que desejava, elogiando suas posturas, e criticou o que acusava de 'defender barbáries'. Além disso, trouxe de volta para a discussão a ideia de 'família tradicional', um conceito inspirado na religião e que se encontra plasmado no Artigo $2^{\circ}$ do projeto defendido pelos "verdadeiros católicos". Mais adiante, o deputado falou um pouco sobre o que eram essas 'barbáries':

Então, senhor presidente, eu acho que é uma vergonha, eu acho que alguns católicos neste Brasil sentem envergonhados e até enojados (enfático) com pessoas que usam a nomenclatura "sou católico" (enfático) e chega aqui vem ser defensor da morte, porque os mesmos que estão aqui fazendo essa falácia aqui são os que defendem o aborto aí, são eles que defendem outras práticas... que vão de encontro ao bem da sociedade ... 
O emprego inespecífico da expressão "outras práticas" dificulta a crítica pelos adversários, mas, ao mesmo tempo, tem seu efeito de sentido garantido. Essa imprecisão sistemática (Edwards \& Potter, 1992) cria uma barreira argumentativa que faz com que o discurso não seja alvo fácil das críticas e possibilita que o essencial do argumento seja inferido e tenha seu peso. Apesar de já terem sido registradas declarações homofóbicas nesta sessão, há um cuidado para não se reforçar a tese dos deputados contrários de que o projeto é uma tentativa de excluir os casais do mesmo sexo da definição de família.

Depois de outras menções, como a da deputada Leila Ribeiro, contrária ao projeto e que questionou a criação, no ensino fundamental e no médio, de uma disciplina chamada 'Educação para família', como prevê o Estatuto, que poderia incorrer na substituição de uma teoria científica por um ensinamento religioso, o deputado Otávio Alves (PRB/AM), que presidiu a sessão durante mais de uma hora, fez a derradeira menção religiosa e reafirmou um dos seus propósitos como deputado:

Em 1999, eu cheguei aqui, sabe por que que a gente lutava nessa Casa? Prá não deixar que essa Casa aprovasse o casamento entre pessoas do mesmo sexo, e o STF [Supremo Tribunal Federal $]$ respeitava essa Casa e não fazia de forma nenhuma a, a, o deboche que fez quando, quando de forma judicial atropelou o legislativo e impôs à sociedade brasileira um direito de império que o juiz tem de fazer o que ele quiser, hoje nós estamos em Eclesiastes 3, "há tempo prá...”, já citaram tanto a Bíblia aqui, PSOL citou, todo mundo citou, me acho no direito de citar, "há tempo prá tudo”, o tempo é de um Estatuto novo prá família brasileira, muito obrigado.

Assim como outros deputados, ele cita um trecho da Bíblia para justificar o projeto do Estatuto, pois já que "há tempo prá tudo", agora é o momento para que esse projeto seja aprovado. É interessante notar que, assim como alguns de seus colegas que fizeram menções diretas ao livro sagrado dos cristãos, ele declara antecipadamente que está prestes a fazer esse tipo de menção. O simples fato de fazer uma declaração religiosa não é o mesmo que dizer que se fará uma declaração religiosa antes de fazê-la de fato: "já citaram tanto a Bíblia aqui, PSOL citou, todo mundo citou, me acho no direito de citar". Nesse caso, há uma necessidade de anunciar a própria ação discursiva com antecedência e justificá-la com base no que outros colegas já vinham fazendo. Na tipologia de relatos oferecida por Semin e Manstead (1983 citado por Potter \& Wetherell, 1987, tradução nossa), essa escusa se chama 'apelo a circunstâncias atenuantes', e é uma forma de aviso prévio ao que será dito em seguida, um pedido para não ser interpretado como um caso isolado.

Em diferentes momentos da história brasileira, políticos e religiosos se articularam para fazer valerem seus interesses (Vital \& Lopes, 2013). Embora o monopólio católicoromano esteja se enfraquecendo, mantém-se, ainda, um monopólio cristão. As religiões são um "elemento ativo e inseparável das dinâmicas culturais e políticas”, tanto numa perspectiva conservadora quanto emancipatória (Burity, 2008, p. 95). Na atualidade, a presença dos atores religiosos na política se intensificou. A esfera pública brasileira é palco de uma forte determinação religiosa em tensão com uma influência reduzida dos "critérios laicos de secularização". Eles se esforçam para criar quadros eleitorais no interior da Igreja, apoiando-se na ideia de que sua presença na política garante a sobrevivência dos valores religiosos (Burity, 2008; Camurça, 2019; Machado, 2012; Ribas, 2008). Católicos (da renovação carismática) e (neo) pentecostais se mobilizam "para que determinadas crenças se convertam em legislação, e o Estado opere com base em alguns valores” (Silva, 2017, p. 242). Nesse contexto, a família nuclear cristã tornou-se um dos valores inegociáveis. 
Como advertem Lanza, Rodrigues e Neves Júnior (2018, p. 201), as concepções de família estão atreladas "à estrutura social, histórica, cultural, econômica e religiosa mais ampla”. Ao desconsiderar a complexidade social, impôs-se, historicamente, o modelo de família nuclear burguesa como ideal, homogeneizou-se e naturalizou-se o conceito de família com interpretações deterministas e generalizantes e se excluíram e estigmatizaram outros arranjos familiares (Bertelli \& Moser, 2018).

As instituições cristãs, fundamentadas em determinada interpretação da Bíblia que exclui "as mediações da modernidade", e na ideia de que representam "a mentalidade da maioria dos brasileiros", defendem uma concepção hierárquico-autoritária de família, conservadora e tradicional, sem considerar as transformações por que tem passado a sociedade (Camurça, 2019, p. 142). O "ativismo religioso" desses grupos políticos tem tido forte influência sobre a definição de políticas públicas (Camurça, 2019; Serra, 2016), pois consideram que questões políticas, sociais e econômicas fazem parte de sua missão religiosa. Reivindicam um lugar de protagonismo embasado no 'discurso dos direitos' e da democracia, com o intuito de ampliar a influência de suas tradições, lideranças e valores, e de se tornarem guardiães da ética e dos valores cristãos (Sung, 2015; Vital \& Lopes, 2013).

A presença dos 'novos movimentos sociais' - os coletivos feministas, o movimento LGBTT etc. - contribuiu para o surgimento de coletivos religiosos mais liberais e para um ativismo religioso conservador (Machado, 2012). A atuação desses atores religiosos conservadores é fruto da presença de múltiplas formas de modernidade, da existência de vários atores políticos que, no campo político e no social, disputam hegemonia.

O Estatuto da Família, que dispõe sobre as diretrizes das políticas públicas voltadas para a família, irá, certamente, ter um impacto decisivo na formulação de todas as políticas sociais cujo pilar de sustentação é a própria família. A proposta de Estatuto aqui analisada, especialmente por meio de sua definição restritiva de família, limita a atenção integral às famílias brasileiras, desconsidera e trata "com preconceito a multiplicidade das famílias existentes" e "desqualifica e inviabiliza qualquer família que fuja da configuração proposta” (Mountian, 2016, p. 47). Ao limitar a definição de entidade familiar 'a homem/mulher e filhos', exclui sumariamente da proteção especial do Estado outros arranjos familiares. Aquino (2015, p. 11), em estudo sobre o conteúdo de discursos dos parlamentares em audiências públicas da mesma comissão, apontou como "evidente" que há conotações homofóbicas no discurso religioso empregado pelos deputados e uma "mistura de crenças pessoais com atuação do Estado". Portanto, o projeto é considerado a "materialização da homofobia parlamentar".

Diversas votações para alterar o projeto foram realizadas ao longo da sessão, todas propostas pela minoria dos deputados contrários e rejeitadas pela maioria favorável ao projeto. Depois de cinco horas de discussão, com críticas, trocas de acusações e bate-bocas constantes, a sessão foi encerrada pelo presidente com a aprovação do projeto e o encaminhamento para a Mesa Diretora da Câmara dos Deputados. Para Trevisan (2013), esse tipo de projeto encontra respaldo no Congresso Nacional, não somente por causa da influência da Frente Parlamentar Evangélica, mas também porque o próprio Congresso, na atualidade, é caracteristicamente conservador, assim como a população que o elege. Portanto, o projeto do Estatuto da Família está na Mesa Diretora da Câmara porque há respaldo político entre os congressistas e tem o apoio indireto da população. Vale destacar que o presidente da Câmara ainda não colocou o projeto em pauta para que o processo de tramitação continue. Porém, foram aprovados outros projetos semelhantes em casas legislativas de alguns estados, algo que sai do âmbito federal a que se propõe a discussão. 


\section{Considerações finais}

Neste artigo, buscamos identificar a construção da factualidade discursiva que sustenta a defesa e a contraposição, por meio de argumentos com fundamentação religiosa, ao projeto do Estatuto da Família, na sessão de conclusão dos trabalhos da comissão especial destinada a proferir parecer sobre esse projeto de lei. Foi possível observar que a construção da factualidade discursiva ampara-se no conteúdo religioso dos argumentos e que os argumentos religiosos ganham fidedignidade através das estratégias retóricas de factualidade. É possível distinguir os argumentos dos deputados favoráveis dos contrários apenas em termos de conteúdo, porque, em relação ao emprego dos dispositivos argumentativos, ambos são equivalentes. Em outras palavras, ambos os lados empregam estratégias semelhantes e lançam mão, em alguns momentos mais do que em outros, do discurso religioso para serem ouvidos. A única diferença entre os argumentos é ao que eles se reportam: ora criticam o laicismo, ora a quebra da laicidade; ora acusam o fundamentalismo, ora ostentam a constitucionalidade. Nota-se, portanto, que os dois lados empregaram argumentos religiosos e estratégias discursivas para construir sua posição atacando seus opositores e se defendendo deles usando a 'mesma moeda'.

\section{Referências}

Antunes, D. C. (2016). Tolerância e democracia hoje: o discurso de deputados em defesa da posição conservadora. Revista Psicologia छ Sociedade, 28(1), 3-13. Recuperado de https://www. scielo.br/pdf/psoc/v28n1/1807-0310-psoc-28-01-00003.pdf.

Aquino, J. C. (2015). Estatuto da Família: a atuação da Frente Parlamentar Evangélica na contramão de direitos a homossexuais. Monografia, Bacharelado em Serviço Social, Universidade de Brasília, Brasília. Recuperado de bdm.unb.br/handle/ 10483/10450.

Bertelli, E. \& Moser, L. (2018). Que família é esta? Mosaicos de diferenças, contradições, discriminações. EM PAUTA, 16(42), 17-33. Recuperado de https://www.e-publicacoes.uerj. br/index.php/revistaempauta/article/view/39404.

Billig, M. (2008). Argumentando e pensando: uma abordagem retórica à Psicologia Social. Vozes.

Burity, J. A. (2008). Religião, política e cultura: Tempo Social, 20(2), 83-113. Recuperado de https://www.revistas.usp.br/ts/article/view/12580.

Câmara dos Deputados. (2015). PL 6583/2013. Inteiro teor. Recuperado de https://www. camara.leg.br/proposicoesWeb/prop mostrarintegra;jsessionid $=559583 \mathrm{BE} 6 \mathrm{~B} 14801 \mathrm{~B} 15518$ 66FEA7638F4.proposicoesWebExterno 1? codteor $=1159761 \&$ filename $=$ PL $+6583 / 2013$.

Câmara dos Deputados. (2020a). Comissões especiais. Recuperado de https://www2.camara. leg.br/atividade-legislativa/comissoes/comissoes-temporarias/especiais.

Câmara dos Deputados. (2020b). Ata da $14^{a}$ reunião ordinária (deliberativa) realizada em 9 de outubro de 2015. Recuperado de https://www.camara.leg.br/internet/ordemdodia/integras/1398275.htm..

Câmara dos Deputados. (2020c). Frentes parlamentares da $55^{a}$ Legislatura. Recuperado de https://www.camara.leg.br/internet/deputado/frentes.asp?leg= $=55$. 
Camurça, M. (2019). Religião, política e espaço público no Brasil: perspectiva histórico/sociológica e a conjuntura das eleições presidenciais de 2018. Estudos de Sociologia, 2(25), 125-159. Recuperado de https://periodicos.ufpe.br/revistas/revsocio/article/view/243765/34005.

Constituição Federal (1988). Constituição da República Federativa do Brasil. Casa Civil. Recuperado de http://www.planalto.gov.br/ccivil 03/constituicao/constituicao compilado.htm.

Edwards, D. (1997). Discourse and cognition. Sage Publications.

Edwards D. \& Potter, J. (1992). Discursive Psychology: inquiries in social construction. Sage Publications.

Lanza, F., Rodrigues, R. R. B., \& Neves Júnior, J.W.A. (2018). Divergências e convergências quanto ao conceito de "família" no semanário católico O São Paulo. Soc. e Cult., 21(2), 195-218. https://doi.org/10.5216/sec.v21i2.56321.

Machado, M. D. C. (2012). Religião, cultura e política. Religião \& Sociedade, 32(2), 29-56. Recuperado de https://www.scielo.br/scielo.php?pid=So100-85872012000200003\&script= sci abstract\&tlng=pt.

Montambeault, F. (2018). Uma Constituição cidadã? Sucessos e limites da institucionalização de um sistema de participação cidadã no Brasil democrático. Estudos Ibero-americanos, 44(2), 261-272. Recuperado de http://revistaseletronicas.pucrs.br/ojs/index.php/iberoamericana/ article/view/29553/17111.

Mountian, I. (2016). Estado laico: democracia, políticas públicas e Psicologia. In Conselho Regional de Psicologia de São Paulo (Org.). Laicidade, Religião, Direitos Humanos e Políticas Públicas (pp. 39-52). CRP-SP. Recuperado de www.crpsp.org/fotos/pdf-2016-06-21-18-16-42.pdf.

Paiva, G. J. (2016). Psicologia, laicidade e políticas públicas em saúde: um campo de oportunidades e ameaças. In Conselho Regional de Psicologia de São Paulo (Org.). Laicidade, Religião, Direitos Humanos e Políticas Públicas (pp. 135-142). CRP-SP. Recuperado de www.crpsp.org/ fotos/pdf-2016-06-21-18-16-42.pdf.

Potter, J. (1998). La representación de la realidad: discurso, retórica y construcción social. Ediciones Paidós Ibérica.

Potter, J. (2004). Discourse Analysis. In M. Hardy \& A. Bryman (Orgs.) Handbook of data analysis. (pp. 607-624). Sage.

Potter, J. (2012). Discourse Analysis and Discursive Psychology. In H. Cooper (Org.), APA Handbook of research methods in psychology: quantitative, qualitative, neuropsychological, and biological (pp. 111-130). American Psychological Association Press.

Potter, J. \& Wetherell, M. (1987). Discourse and Social Psychology: beyond attitudes and behavior. Sage Publications.

Ribas, A. C. (2008). Família e religião. Antíteses, 1(1), 254-259. Recuperado de http://www.uel. br/revistas/uel/index.php/antiteses.

Rocha, E. (2008). A Constituição Cidadã e a institucionalização dos espaços de participação social: avanços e desafios. In T. F. Vaz, J. S. Musse, \& R. F. Santos (Orgs.), 20 anos da Constituição Cidadã: avaliação e desafios da seguridade social (pp. 131-148). ANFIP.

Serra, C. A. (2016). Fundamentalismo e alteridade no encontro entre Psicologia e Religião. In Conselho Regional de Psicologia de São Paulo (Org.), Laicidade, Religião, Direitos Humanos e Políticas Públicas (pp. 73-78). CRP-SP. Recuperado de www.crpsp.org/fotos/pdf-2016-0621-18-16-42.pdf. 
Silva, L. G. T. (2017). Religião e política no Brasil. Latino-América: Revista de estudios Latinoamericanos, 64, 223-256. Recuperado de https://www.sciencedirect.com/science/article/pii/ $\underline{\mathrm{S} 166585741730008 \mathrm{X}}$.

Sung, J. M. (2015). Prosperidade sim, família homossexual, não! A nova classe média evangélica. Psicologia USP, 26(1), 43-5 1. Recuperado de http://dx.doi.org/10.1590/0103-6564D20140011.

Trevisan, J. (2013). A Frente Parlamentar Evangélica: força política no estado laico brasileiro. Numen: Revista de Estudos e Pesquisa da Religião, 16(1), 581-609. Recuperado de https://periodicos.ufjf.br/index.php/numen/issue/view/937.

Vital, C. C. \& Lopes, P. V. L. (2013). Religião e política: uma análise da atuação de parlamentares evangélicos sobre direitos das mulheres e de LGBTs no Brasil. Fundação Heinrich Böll. Recuperado de https://br.boell.org/pt-br/2013/05/29/religiao-e-politica-uma-analise-da-atuacao-de-parlamentares-evangelicos-sobre-direitos-0.

\section{JERBBSON DIAS DOS SANTOS \\ https://orcid.org/0000-0003-4550-6489}

Graduado em Psicologia pela Universidade Estadual da Paraíba, Campina Grande/PB.

E-mail: jerbbson@gmail.com

\section{THELMA MARIA GRISI VELÔSO \\ https://orcid.org/0000-0003-0447-7490}

Doutora em Sociologia pela Universidade Estadual Paulista (UNESP, campus de Araraquara/SP); Professora do Programa de Pós-graduação em Serviço Social e do Programa de Pós-graduação em Psicologia da Saúde da Universidade Estadual da Paraíba (UEPB), Campina Grande/PB.

E-mail: tgrisiveloso@gmail.com

\begin{tabular}{|l|l|}
\hline \multirow{4}{*}{ Histórico } & Submissão: 13/05/2020 \\
& $1^{\text {a }}$. Revisão: 11/11/2020 \\
& $2^{a}$. Revisão: 17/12/2020 \\
& Aceite: 06/04/2021 \\
\hline & Concepção: J.D.S.; T.M.G.V. \\
& Coleta de dados: J.D.S. \\
& Análise de dados: J.D.S.; T.M.G.V. \\
Contribuição & Elaboração do manuscrito: J.D.S.; T.M.G.V. \\
dos autores & Revisões críticas de conteúdo intelectual importante: \\
& J.D.S.; T.M.G.V. \\
& Aprovação final do manuscrito: J.D.S.; T.M.G.V. \\
\hline \multirow{2}{*}{ Financiamento } & Não houve financiamento. \\
\hline
\end{tabular}

